\title{
65 yaş ve üzeri olgular için düzenlenen adli raporların retrospektif incelenmesi
}

\author{
Retrospective assessment of forensic reports prepared for 65 years of age \\ and older cases \\ Hülya Güler ${ }^{1}$ \\ Mehmet Semih Belpınar²
Ahsen Kaya ${ }^{1}$
Ender Şenol ${ }^{1} \mathbb{B}$ \\ ${ }^{1}$ Ege Üniversitesi, Tıp Fakültesi, Adli Tıp Anabilim Dalı, İzmir, Türkiye \\ ${ }^{2}$ İstanbul Üniversitesi, Cerrahpaşa Tıp Fakültesi, Kardiyoloji Anabilim Dalı, İstanbul, Türkiye
}

Öz

Amaç: Bu çalışmada, adli raporları düzenlenen 65 yaş ve üzeri olguların kayıtları incelenerek, yaşlılardaki yaralanma özelliklerinin belirlenmesi ve bu travmaların önlenmesi için alınacak tedbirlere dikkat çekilmesi amaçlanmıştır.

Gereç ve Yöntem: Ege Üniversitesi Tıp Fakültesi Adli Tıp Anabilim Dalında 1 Ocak 2014-31 Aralık 2015 tarihleri arasında düzenlenen toplam 2471 rapor arasından, olay tarihindeki yaşı 65 yaş ve üzeri olan 101 olgunun raporu geriye dönük olarak incelendi. Veriler istatistik programına aktarılarak değerlendirildi.

Bulgular: Raporu değerlendirilen 101 olgunun 63'ü $(\% 62,4)$ erkekti. Ortalama yaş 72,8 76,04 ve maksimum yaş 89 idi. Trafik kazaları \%82,3 ile en sık travma nedeni idi. Ekstremiteler en çok etkilenen vücut bölgesiydi.

Sonuç: Yaşlı bireyler söz konusu olduğunda, diğer yaş gruplarına göre benzer travmaların kişide oluşturduğu hasar çok daha fazla olabilmektedir. Bu nedenle, 65 yaş ve üzeri olgularda en önemli travma nedeni olarak tespit edilen trafik kazalarının önlenmesi için gerekli tedbirlerin alınması mortalite ve morbiditeyi azaltmada etkili bir adım olacaktır. Yaşlılarda meydana gelen travmaların özelliklerinin açıklanmasının, bu konuda alınacak önlemlerin belirlenmesine katkıda bulunacağı düşünülmektedir.

Anahtar Sözcükler: Yaşı, adli tıp, travma, trafik kazası.

\begin{abstract}
Aim: It was aimed to examine the records of individuals 65 years of age and older for which forensic reports were prepared, to identify injury characteristics in older people and to draw attention to the precautions to be taken to prevent older people from traumas in this study.

Materials and Methods: Among the total of 2471 forensic reports which are prepared between 01 January 2014 and 31 December 2015 in Department of Forensic Medicine of Ege University Faculty of Medicine, the reports of 101 cases who were 65 years of age and older at the time of event were evaluated retrospectively. The data were evaluated by transferring to statistical program.

Results: Of the 101 cases evaluated, 63 (62.4\%) were male. The mean age was $72.8 \pm 6.04$ and maximum age was 89 years old. The traffic accidents were the most common cause of trauma (82.3\%). The extremities were the most affected body region.
\end{abstract}

\footnotetext{
Sorumlu yazar: Hülya Güler

Ege Üniversitesi, Tıp Fakültesi, Adli Tıp Anabilim Dalı, İzmir,

Türkiye

E-posta: drhulyaguler@yahoo.com

Başvuru Tarihi: 14.11.2019 Kabul Tarihi: 18.03.2020
} 
Conclusions: When the damages caused by similar traumas are compared in older people with other age groups, they would be much harmful in older people. Therefore, even taking the necessary measures to prevent traffic accidents which were determined as the most important cause of trauma in the cases aged 65 years and older, would be an effective step in reducing mortality and morbidity. Explaining the characteristics of traumas occurring in older people is thought to contribute to the determination of the measures to be taken in this regard.

Keywords: Older people, forensic medicine, trauma, traffic accident.

\section{Giriş}

Teknolojinin gelişmesi, zaman içerisinde yaşam kalitesinin artması ile insan ömrünün uzamasına, toplumsal rollerin değişmesine dolayısıyla kronolojik ve sosyal olarak yaşlı tanımının değişmesine neden olmaktadır. Günümüzde gelişmiş ülkelerde "yaşlı" kavramı, kronolojik olarak 65 yaş ve üzeri olarak kabul edilmekte ve yaşlııık sınıflandırması; erken (65-74 yaş), orta (75-84 yaş) ve ileri (85 yaş ve üzeri) yaşlılık evresi şeklinde yapılmaktadır (1-4). Bununla birlikte, Dünya Sağlık Örgütü (DSÖ) yakın zamanda yeni bir sınıflama yapmış olup, 66-79 yaş arası "orta yaş", 80-99 yaş arası "yaşlı", 100 yaş ve üzeri "uzun yaşayan yaşlılar" olarak tanımlanmıştır (5).

Kronolojik olarak yaşlı tanımında çeşitli değişiklikler yapılmakla birlikte, çalışmalar, dünyada doğum oranındaki düşüş ve insan ömründeki uzama ile birlikte yaşlı nüfusun arttığını göstermektedir (1, 2, 6-10). Ülkemiz de aynı nedenlerle yaşlı nüfusun giderek arttığı ülkeler arasındadır (1, 2, 6-8, 10, 11). Türkiye Cumhuriyeti Kalkınma Bakanlığı 10. Kalkınma Planı (2014-2018) Özel İhtisas Komisyonu raporuna göre; 2002 yılında dünyada 65 yaş ve üstü nüfus 440 milyon olup, bu sayı toplam dünya nüfusunun \%6'sını oluşturmaktadır (9). 2020 yılında yaşlı nüfusun neredeyse ikiye katlanması, 2050 'de ise 3 katından fazla olması beklenmektedir (9). Türkiye İstatistik Kurumu (TÜIK) verilerine göre de, ülkemizde 65 yaş ve üstü nüfus 2015 yılında yaklaşık 6,5 milyon olmuştur (12). Birleşmiş Milletler verilerine göre, 1950-2015 yılları arasında yaşı nüfus dünyada 2,5 kat artarken, Türkiye'de 5 kattan fazla artış göstermiş ve 2050'de 2015'e göre yaşlı nüfusun 3 katına çıkacağı tahmin edilmektedir (13). Bu veriler, Türkiye'nin çok daha hızlı yaşlanan bir toplum olduğunu göstermektedir.

Yaşlı bireylerin genel olarak gençlere göre sosyal faaliyetlere daha az katılmaları ve dışarıda geçirdikleri sürelerin nispeten daha az olması, dış etkenlere maruziyetlerinin de gençlere göre daha az olmasına neden olmaktadır (7). Ancak teknolojik gelişmelerle birlikte yaşlı bireylerin daha sağlıklı ve aktif bir yaşam sürme olanakları da arttığından travmaya maruz kalma risklerinde de artış görülebilmektedir (7, 10, 11, 14, 15). Bununla birlikte, yaşlanmanın neden olduğu zihinsel faaliyetlerde yavaşlama, dikkat eksikliği, algılama bozukluğu, işitme, görme gibi duysal fonksiyonlarda ve kas gücünde azalma, reflekslerde gecikme gibi negatif fizyopatolojik değişiklikler de yaşlı popülasyonun travmaya maruz kalma riskini arttırabilmektedir (6-8, 10, 14-16). Ayrıca yaşlanmaya bağlı olarak bireylerde meydana gelen farmakodinamik, metabolik ve fizyolojik değişiklikler travmadan kaçınma yeteneği ile oluşan travmanın stresi ile başa çıkma yeteneğini de azaltmaktadır $(6-8,10$, 11, 14-17). Bu nedenle, travmalar yaşlı kişilerde gençlere göre daha ağır seyretmekte, ciddi hasarlar oluşabilmekte, hastanede kalış süreleri artmakta ve daha fazla engelliliğe sebep olabilmektedir $(6-8,10,11,15-20)$. Çoklu travmalı yaşlı olgular arasında bir değerlendirme yapıldığında da özellikle 75 yaş üzerinde mortalite riskinin daha da arttığı belirtilmiştir (21).

Bu çalışmada adli raporu düzenlenen 65 yaş ve üzeri olgulara ait kayıtlar incelenerek, yaşlı bireylerde travma özelliklerinin ortaya konulması ve yaşı bireyleri travmalardan korumada alınabilecek önlemlere dikkat çekmek amaçlandı.

\section{Gereç ve Yöntem}

Adli Tıp Anabilim Dalında 01 Ocak 2014-31 Aralık 2015 tarihleri arasında adli raporu düzenlenen toplam 2471 adli olguya ait rapor arasından, olay tarihinde 65 yaş ve üzerinde olan 101 (\%4) olgunun adli raporları ve raporlara esas tıbbi kayıtları, etik kurul onayı alınmasının ardından cinsiyet, olay tarihindeki yaş, yaralanma nedeni, yaralanan vücut bölgesi, konsültasyon istenen branş açısından retrospektif olarak incelendi. Veriler SPSS for Windows 18.0 istatistik programına aktarıldı ve frekans analizi uygulanarak değerlendirildi.

\section{Bulgular}

Çalışma kapsamında, olay tarihinde 65 yaş ve üzeri olan 101 olguya ait adli rapor 
değerlendirildi. Olguların 63'ü $(\% 62,4)$ erkek, 38'i $(\% 37,6)$ kadındı. Maksimum yaş 89 olup yaş ortalaması 72,8 $\pm 6,04$ idi. Olgular $65-74,75-84$ ve 85 yaş ve üzeri olarak üç yaş grubuna ayrıldığında, en çok 65-74 yaş grubu için rapor düzenlendiği $(n=71)$ görüldü.

Olay türüne göre, ilk sırada trafik kazaları $(n=83)$ ve ikinci sırada etkili eylem olguları $(n=6)$ yer almakta idi. Olay türlerinin yaş gruplarına ve cinsiyete göre dağılımı Tablo-1'de belirtildi.

Trafik kazaları, oluş şekline göre sınıflandırıldığında, en çok araç dışı trafik kazasının ( $n=51)$ söz konusu olduğu ve bunu sırasıyla araç içi trafik kazasının $(n=26)$, motosiklet $(n=1)$ ve traktör kazasının $(n=1)$ takip ettiği görüldü. Trafik kazası türlerinin yaş grupları ve cinsiyete göre dağılımı Tablo-2'de verildi.

Yaralanma bölgeleri incelendiğinde ilk sırada üst ekstremite $(n=46)$ ve alt ekstremitenin $(n=46), 2$. sırada ise yüz bölgesinin $(n=42)$ yer aldığı tespit edildi. Olay türü (Trafik kazası şekilleri ve diğer yaralanmalar) ile yaralanma bölgelerinin karşılaştırılması Tablo-3'te belirtildi.

Rapor düzenlenmesi aşamasında en fazla konsültasyon istenen bölümün Ortopedi $(n=19)$ olduğu saptandı. Ortopedi konsültasyonu istenen olguların 16'sı trafik kazası, 2'si düşme, 1'i de etkili eylem olgusuydu.

Tablo-1. Olay türlerinin yaş gruplarına ve cinsiyete göre dağılımı.

\begin{tabular}{|c|c|c|c|c|c|c|c|c|c|}
\hline \multirow{3}{*}{ Olay türü } & \multicolumn{6}{|c|}{ Yaş grupları } & \multicolumn{2}{|c|}{ Cinsiyet } & \multirow{3}{*}{ Toplam } \\
\hline & \multicolumn{2}{|c|}{$65-74$} & \multicolumn{2}{|c|}{$75-84$} & \multicolumn{2}{|c|}{85 ve üzeri } & \multirow{2}{*}{ Kadın } & \multirow{2}{*}{ Erkek } & \\
\hline & $\mathrm{K}$ & $\mathbf{E}$ & $\mathrm{K}$ & $E$ & $\mathrm{~K}$ & $\mathbf{E}$ & & & \\
\hline Trafik kazası & 21 & 37 & 9 & 12 & 1 & 3 & 31 & 52 & 83 \\
\hline Etkili eylem & 0 & 4 & 1 & 1 & 0 & 0 & 1 & 5 & 6 \\
\hline Düşme & 3 & 1 & 0 & 0 & 1 & 0 & 4 & 1 & 5 \\
\hline Hekim hatası & 0 & 1 & 0 & 1 & 0 & 0 & 0 & 2 & 2 \\
\hline $\mathrm{KDAY}^{*}$ & 0 & 1 & 0 & 0 & 0 & 0 & 0 & 1 & 1 \\
\hline $\mathrm{CO}^{* *}$ & 1 & 0 & 0 & 0 & 0 & 0 & 1 & 0 & 1 \\
\hline Kesici aletle suicid & 0 & 0 & 1 & 0 & 0 & 0 & 1 & 0 & 1 \\
\hline $\mathrm{KDAY}^{\star}+$ Etkili eylem & 0 & 1 & 0 & 0 & 0 & 0 & 0 & 1 & 1 \\
\hline Tetkik İstemi*** & 0 & 1 & 0 & 0 & 0 & 0 & 0 & 1 & 1 \\
\hline Toplam & 25 & 46 & 11 & 14 & 2 & 3 & 38 & 63 & 101 \\
\hline
\end{tabular}

Tablo-2. Trafik kazası türlerinin yaş grupları ve cinsiyete göre dağılımı.

\begin{tabular}{|c|c|c|c|c|}
\hline \multirow{2}{*}{ Yaş Aralığı } & \multirow{2}{*}{ Olay Türü } & \multicolumn{2}{|c|}{ Cinsiyet } & \multirow{2}{*}{ Toplam } \\
\hline & & Erkek & Kadın & \\
\hline \multirow{5}{*}{$65-74$} & Araç dışı trafik kazası & 21 & 13 & 34 \\
\hline & Araç içi trafik kazası & 10 & 8 & 18 \\
\hline & Motosiklet kazası & 5 & 0 & 5 \\
\hline & Traktör kazası & 1 & 0 & 1 \\
\hline & Toplam & 37 & 21 & 58 \\
\hline \multirow{3}{*}{$75-84$} & Araç dışı trafik kazası & 7 & 7 & 14 \\
\hline & Araç içi trafik kazası & 5 & 2 & 7 \\
\hline & Toplam & 12 & 9 & 21 \\
\hline \multirow{3}{*}{85 ve üzeri } & Araç dışı trafik kazası & 2 & 1 & 3 \\
\hline & Araç içi trafik kazası & 1 & 0 & 1 \\
\hline & Toplam & 3 & 1 & 4 \\
\hline
\end{tabular}


Tablo-3. Olay türü ile yaralanma bölgelerinin karşılaştırılması.

\begin{tabular}{lcccccccc}
\hline & \multicolumn{7}{c}{ Yaralanma Bölgeleri } \\
\cline { 2 - 8 } Olay türü & Yüz & $\begin{array}{c}\text { Baş - } \\
\text { boyun }\end{array}$ & Toraks & $\begin{array}{c}\text { Karın- } \\
\text { pelvis }\end{array}$ & $\begin{array}{c}\text { Üst } \\
\text { ekstremite }\end{array}$ & $\begin{array}{c}\text { Alt } \\
\text { ekstremite }\end{array}$ & Omurga & Toplam \\
\hline $\begin{array}{l}\text { Araç dışı } \\
\text { trafik kazası }\end{array}$ & 21 & 20 & 20 & 19 & 24 & 25 & 11 & 140 \\
$\begin{array}{l}\text { Araç içi trafik } \\
\text { kazası }\end{array}$ & 10 & 13 & 11 & 10 & 10 & 11 & 8 & 73 \\
$\begin{array}{l}\text { Diğer* } \\
\text { Motosiklet }\end{array}$ & 7 & 3 & 2 & 0 & 7 & 6 & 0 & 25 \\
kazası & 3 & 2 & 4 & 2 & 5 & 4 & 0 & 20 \\
$\begin{array}{l}\text { Traktör } \\
\text { kazası }\end{array}$ & 1 & 0 & 0 & 0 & 0 & 0 & 0 & 1 \\
Toplam & 42 & 38 & 37 & 31 & 46 & 46 & 19 & $259^{* *}$ \\
\hline
\end{tabular}

${ }^{*}$ Etkili eylem $(n=6)$, düşme $(n=5)$, kesici-delici alet yaralanması $(n=1)$, karbonmonoksit zehirlenmesi $(n=1)$, hekim hatası iddiası $(n=2)$, kesici aletle suisid $(n=1)$, tetkik istemi $(n=1)$, etkili eylem ile birlikte kesici-delici alet yaralanması $(n=1)$.

**Aynı olguda birden fazla yaralanma bölgesi olduğu için yaralanma bölgelerinin toplamı olgu sayısından fazladır.

\section{Tartışma}

Hızla yaşlanan bir toplum olarak ülkemizde, yaşlılar hakkında yapılan çalışmaların giderek daha da önem kazanması kaçınılmazdır. Yaşlı bireylerde travma özelliklerinin belirlenmesi ve bu doğrultuda koruma tedbirlerinin alınması amacıyla yapılan bu çalışmada, iki yıllık süre içinde adli raporu düzenlenen, yaşı 65 ve üzeri olan 101 olguya ait raporlar retrospektif olarak incelendi. Elbette ki, daha yüksek olgu sayılarına sahip çalışmalar yapılması bu konuda koruma tedbirlerinin alınmasında daha etkili olacaktır.

Sunulan çalışmada, literatürle uyumlu olarak, erkek olgu sayısının daha fazla olduğu görüldü $(6,7,11,16,17,22)$. Bu durum, erkeklerin sosyal yaşamda daha aktif bir rol almaları, ev dışı ortamlarda kadınlara göre daha fazla zaman geçirmeleri ile ilişkilendirildi. Bununla birlikte, geriatrik gruplarla yapılan ve kadın sayısının daha fazla olduğu çalışmalara da rastlandı $(8,10$, 18, 19).

$\mathrm{Bu}$ çalışmada yaş ortalaması $72,8 \pm 6,04$ olarak tespit edilmiş olup, Bursa'da yapılan bir çalışmada da yaş ortalamasının aynı şekilde $72,07 \pm 6,00$ olduğu görüldü (11). Genel olarak bakıldığında çalışmalarda, yaş ortalamasının erken yaşlılık evresi ile uyumlu olduğu dikkati çekti $(6,7,15,16)$. Çalışmamızda ayrıca erken yaşlılık evresindeki olgu sayısının diğer yaş gruplarına göre daha fazla olduğu belirlendi. Bunun sebebinin, erken yaşlılık evresindeki bireylerin diğer yaşlı bireylere göre daha hareketli olmaları ve dolayısıyla ev dışına yalnız başına çıkabilmeleri, sosyal hayata diğer yaş gruplarına göre daha fazla katılabilmeleri olabileceği düşünüldü.

Çalışmamızda tüm yaş gruplarında en sık görülen olay türünün trafik kazası (özellikle araç dışı trafik kazası) olduğu saptandı. Yaşlı travma olgularının araştırıldığı çalışmalarda genel olarak en sık başvuru sebebinin trafik kazaları olduğu görüldü $(6,7,11,15)$. Yaşlılarda refleks, algı ve duyu fonksiyonlarındaki azalmanın, trafik kazasına maruz kalmada en önemli etken olduğu ve bu nedenle travma tiplerinden en sık trafik kazalarıyla karşılaşıldığı düşünüldü. Bununla birlikte, bazı çalışmalarda trafik kazalarının ikinci sırada olduğu, düşmelerin birinci sıraya yerleştiği görüldü $(8,10,16,18,19)$. Bursa'da yapılan bir çalışmada ise farklı olarak ilk sırada fiziksel saldırı, ikinci sırada trafik kazaları yer almaktaydı (17). Güneytepe ve ark. çalışmalarında, en sık görülen olay türünün yaş aralığına göre değiştiğini, erken yaşıılık evresindeki yaşlılarda trafik kazalarının ilk sırada olduğunu, 75 yaş üstü olgularda ise düşmelerin ilk sırada, trafik kazalarının ikinci sırada yer aldığını belirtmişlerdir (11). Bolivya'da yapılan ve yaş ortalamasının 75 yaş olduğu bir başka çalışmada da düşmenin ilk sıradaki travma şekli olduğu belirtilmektedir (18). Yaşı populasyonda trafik kazasına nazaran düşmenin en sık görülen travma olarak belirtildiği bir çalışmada bu durum, çalışmaya dahil edilen yaşlıların daha bağımlı hareket yeteneğine sahip olmaları ve motorlu araç kullanabilme kabiliyetlerinin azalmış olması ile açıklanmıştır (19). 
Çalışmamızda ikinci ve üçüncü sıradaki olay türleri sırasıyla etkili eylem $(n=6)$ ve düşme $(n=5)$ olarak belirlenmiş olup olgu sayıları birbirine oldukça yakındır. Olgu sayısı açısından daha kapsamlı bir çalışma yapıldığında, etkili eylem ve düşme arasındaki sıralamanın da değişebileceği düşünülmektedir. Literatür incelemesinde bazı çalışmalarda düşmenin $(11,15)$, bazılarında ise etkili eylem olaylarının ikinci sırada yer aldığı görüldü $(6,7)$. Zamanının büyük çoğunluğunu evde geçiren, ergonomik açıdan ev içi dizaynın konforlu ve rahat hareket etmeye uygun olmadığı ortamlarda yaşayan yaşlı bireylerin özellikle ev içinde düşme olayları ile etkili eylem olaylarına göre nispeten daha sık karşılaşabilecekleri düşünülmektedir.

Sunulan çalışmada, olgu sayısı 101 iken yaralanma bölgesi sayısı olgu sayısından fazla tespit edilmiş olup alt ve üst ekstremiteler en sık yaralanan travma bölgesi olarak saptanmıştır. Buna bağlı olarak da rapor düzenlenmesi aşamasında en sık konsültasyon istenen branşın Ortopedi olması uyumlu bir bulgu olarak değerlendirilmiştir. Literatürde, ekstremiteler ve baş-boyun bölgesi en sık yaralanan travma bölgeleri olarak belirtilmektedir $(7,8,10,11,15$ 17). Çalışmamızda ekstremite yaralanmalarının sık görülme sebebinin; en sık saptanan olay türünün trafik kazaları, özellikle de araç dışı trafik kazaları olması, yaşı kişilerde genel kas kuvvetsizliği-reflekslerde gecikme nedenli travmadan kaçınabilme yetersizliğiyle birlikte osteoporoza bağlı kemik kırılganlığının artması ve uzun kemiklerin yer aldığı ekstremitelerin bundan etkilenmesi olarak değerlendirildi.

\section{Sonuç}

Travma sonucu meydana gelen yaralanmalar kişiye ve ülkeye oldukça ağır maliyetler getirmektedir. Yaşlı bireyler söz konusu olduğunda benzer travmanın kişide oluşturduğu hasar çok daha fazla olabilmektedir. Ülkemizde hem yaşlı nüfusun artması, hem de kalabalık aile yapısından çekirdek aile yapısına yönelimin artması nedenleriyle, yaşlı bireylerin işlerini kendilerinin yapmak durumunda kalması, dışarıyla temaslarının daha fazla olmasına, dolayısıyla eskiye göre adli olaylarla daha sık karşılaşmalarına neden olmaktadır.

En sık görülen travma türünün trafik kazaları olduğu göz önünde bulundurulduğunda, başta trafikte olmak üzere, ev içi dahil tüm yaşam alanlarında yaşılıarın hayatını kolaylaştıracak önlemler alınmasının, travmalara bağlı maddimanevi kayıpları azaltacağı, engelliliği ve başkalarına bağımlıı̆ı önleyeceği, dolayısıyla da yaşlılarda travma nedenli mortalite ve morbiditeyi azaltacağı düşünülmektedir. Trafikte karşıdan karşıya geçmelerini kolayca sağlayacak düzenlemelerin yapılması, sürücülerin daha dikkatli olması için yaya önceliği konusunda bilinçlendirilmeleri, özellikle motor ve mental fonksiyonlar açısından yetersiz olan, yardımsız hareket etmekte güçlük çeken yaşıların yalnız bırakılmamaları, ev içi kazaları ve özellikle düşmeleri azaltabilecek, günlük yaşamı kolaylaştırabilecek şekilde (güvenli hareket yollarının oluşturulması, koridor, banyo gibi alanlara destek barlarının takılması, minimalist yaşam alanlarının oluşturulması gibi) ev içi dizaynlar yapılması kaza sonucu yaralanmaları büyük ölçüde azaltabilecek küçük ve basit önlemlerdir.

Travmaya maruz kalmış yaşlı olgularda ek hastalıkların varlığı, çoklu ilaç kullanımı, biyolojik ve fizyolojik rezervlerin yetersizliği gibi etkenler bu olgulardaki multidisipliner yaklaşımı daha da ön plana çıkarmaktadır. Bu nedenle, travmalı yaşı bir olguya müdahalede deneyimli ekiplerin görev almasının, tedavide daha etkili sonuçlar alınmasına, dolayısıyla kişi, ailesi ve ülke düzeyindeki olumsuz etkilenme düzeyinin azaltılmasına katkı sağlayacağı düşünülmektedir.

\section{Açıklamalar}

Bu çalışma 13-16 Ekim 2016 tarihlerinde BaküAzerbaycan'da yapılan 1. Uluslararası TURAZ Adli Tıp ve Patoloji Kongresi'nde sözel bildiri olarak sunulmuş ve kongre bildiri özet kitabında yayımlanmıştır.

Çıkar Çatışması: Bu çalışma herhangi bir kişi, kurum ya da kuruluş tarafından desteklenmemiştir ve yazarlar arasında çıkar çatışması yoktur. 


\section{Kaynaklar}

1. Beğer T, Yavuzer H. Yaşlılık ve yaşlılık epidemiyolojisi. Klinik Gelişim 2012;25:1-3.

2. Soyuer F, Soyuer A. Yaşılıık ve fiziksel aktivite. İnönü Üniversitesi Tıp Fakültesi Dergisi 2008;15(3):219-24.

3. Tümerdem Y. Gerçek yaş. Turkish Journal of Geriatrics 2006;9(3):195-6.

4. Kowal P, Dowd JE. Definition of an older person. Proposed working definition of an older person in Africa for the MDS Project. Geneva: World Health Organization; 2001. https://www.researchgate.net/publication/264534627_Definition_of_an_older_person_Proposed_working_defi nition_of_an_older_person_in_Africa_for_the_MDS_Project. Erişim tarihi: 29.08.2019.

5. Tunggono V. 65 years old is still young! How old is old? https://en.brilio.net/news/65-years-old-is-still-young65-years-old-is-still-young-1601205.html. Erişim Tarihi: 20.08.2019.

6. Kandiş H, Karakuş A, Katırcı Y, Karapolat S, Kara İH. Geriatrik yaş grubu ve adli travmalar. Turkish Journal of Geriatrics 2011;14(3):193-8.

7. Gündüz T, Karbeyaz K, Yüksel F, Balcı Y. Yeni Türk Ceza Kanunu çerçevesinde geriatrik olgulara düzenlenen adli raporların değerlendirilmesi. Turkish Journal of Geriatrics 2010;13(1):8-12.

8. Gamsız Bilgin N, Mert E. Geriatrik yaş grubu adli olguların özellikleri. Türk Geriatri Dergisi 2005;8(1):13-6.

9. T.C. Kalkınma Bakanlığı Onuncu Kalkınma Planı 2014-2018 Yaşlanma Özel İhtisas Komisyonu Raporu, Ankara 2014. ISBN 978-605-9041-00-3, Yayın no: KB: 2900 - ÖIK:740. http://www.sbb.gov.tr/wpcontent/uploads/2018/10/10_Yaslanma.pdf. Erişim tarihi 21.01.2019.

10. Aktürk A, Avcı A, Gülen M, Ay MO, İçme F, Satar S. Acil Tıp Anabilim Dalına travma sonrası kabul edilen geriatrik hastaların ileriye dönük analizi. Cukurova Medical Journal 2013;38(4):687-95.

11. Güneytepe Üí, Akköse Aydın Ş, Gökgöz Ş, Özgüç H, Ocakoğlu G, Aktaş H. Yaşlı travma olgularında mortaliteye etki eden faktörler ve skorlama sistemleri. Uludağ Üniversitesi Tıp Fakültesi Dergisi 2008;34(1):15-9.

12. İstatistiklerle yaşlılar, 2015. Türkiye İstatistik Kurumu Haber Bülteni, Sayı 21520, 17 Mart 2016, saat 10:00. www.tuik.gov.tr/PdfGetir.do?id=21520, erişim tarihi 14.10.2016.

13. United Nations, Department of Economic and Social Affairs, Population division (2015). World population prospects: $\quad$ The $2015 \quad$ revision, https://www.un.org/en/development/desa/population/publications/pdf/ageing/WPA2015_Report.pdf, Erişim tarihi: 29.08.2019.

14. Jacobs DG. Special considerations in geriatric injury. Curr Opin Crit Care 2003;9(6):535-9.

15. Akköse Aydın Ş, Bulut M, Fedakar R, Özgürer A, Özdemir F. Bursa'daki travmalı yaşlı hastalar. Ulus Travma Acil Cerrahi Derg 2006;12(3):230-4.

16. Şen Tanrıkulu C, Tanrıkulu Y. Geriatrik popülasyonda travma analizi: Kesitsel çalışma. Yeni Tıp Dergisi 2013;30(2):100-4.

17. Durak D, Ural MN, Fedakar R, Gürses MS, Akan O, Türkmen İnanır N, Çetin S. Geriatrik adli olgularda travmanın yeri. Adli Tıp Bülteni 2016;21(1):23-5. DOI: https://doi.org/10.17986/blm.2016116596

18. Ludi E, Boeck M, South S, Monasterio J, Swaroop M, Foianini E. Geriatric trauma in Santa Cruz, Bolivia. Journal of Surgical Research 2019;244:212-7. DOI: https://doi.org/10.1016/j.jss.2019.06.042

19. Naraynsingha R, Sammy I, Paul JF, Nunes P. Trauma in the elderly in Trinidad and Tobago: a crosssectional study. Eur J Emerg Med 2015;22(3):219-21. DOI: https://doi.org/10.1097/MEJ.0000000000000196

20. Ringen AH, Gaski IA, Rustad H, Skaga NO, Gaarder C, Naess PA. Improvement in geriatric trauma outcomes in an evolving trauma system. Trauma Surg Acute Care Open 2019;4:e000282. DOI: http://dx.doi.org/10.1136/tsaco-2018-000282

21. Vries R de, Reiningaa IHF, Graaf MW, Heineman E, Moumni M, Wendt KW. Older polytrauma: Mortality and complications. Injury 2019;50(8):1440-7. DOI: https://doi.org/10.1016/j.injury.2019.06.024

22. Karbeyaz K, Balci I, Simsek U. 2019. A 20 years analysis of fatal traffic accidents in elderly; Eskisehir Turkey, Osmangazi Journal of Medicine, DOI: https://doi.org/10.20515/otd.512471 